Ultra Clean Transportation Fuels Program

Report issued: February 2006

\title{
Discovery of New NOx Reduction Catalysts for CIDI Engines Using Combinatorial Techniques (Cooperative Agreement Number: DE-FC26-02NT41218 )
}

\author{
Annual Technical Progress Report (FY05) \\ for October 1, 2004, through September 30, 2005
}

\begin{abstract}
Richard J. Blint (GM), Gerald Koermer (Engelhard Corporation), George Fitzgerald (Accelrys, Inc.)
\end{abstract}

\author{
General Motors Powertrain \\ 895 Joslyn Avenue \\ Pontiac, MI 48340
}

\author{
Engelhard Corporation \\ 101 Wood Avenue, P.O. Box 770 \\ Iselin, NJ 08830
}

\author{
Accelrys Inc \\ 10188 Telesis Court, Suite 100 \\ San Diego, CA 92121
}

\begin{abstract}
This report was prepared as an account of work sponsored by an agency of the United States Government. Neither the United States Government nor any agency thereof, nor any of their employees, makes any warranty, express or implied, or assumes any legal liability or responsibility for the accuracy, completeness, or usefulness of any information, apparatus, product, or process disclosed, or represents that its use would not infringe privately owned rights. Reference herein to any specific commercial product, process, or service by trade name, trademark, manufacturer, or otherwise does not necessarily constitute or imply its endorsement, recommendation, or favoring by the United States Government or any agency thereof. The views and opinions of authors expressed herein do not necessarily state or reflect those of the United States Government or any agency thereof.
\end{abstract}




\begin{abstract}
This project for the discovery of new lean reduction NOx catalysts was initiated on August 16th, 2002 and is now into its fourth year. Several materials have already been identified as NOx reduction catalysts for possible future application. NOx reduction catalysts are a critical need in the North American vehicle market since these catalysts are needed to enable both diesels and lean gasoline engines to meet the 2007-2010 emission standards. Hydrocarbon selective catalytic reduction (SCR) is a preferred technology since it requires no infrastructure changes (as may be expected for urea SCR) and most likely has the simplest engine control strategy of the three proposed NOx reduction approaches. The use of fast throughput techniques and informatics greatly enhances the possibility of discovering new NOx reduction catalysts. Using fast throughput techniques this project has already screened over 3000 new materials and evaluates hundreds of new materials a month. Evaluating such a high number of new materials puts this approach into a very different paradigm than previous discovery approaches for new NOx reduction catalysts. With so much data on materials it is necessary to use statistical techniques to identify the potential catalysts and these statistical techniques are needed to optimize compositions of the multi-component materials that are identified under the program as possible new lean NOx catalysts. Several new materials have conversions in excess of $80 \%$ at temperatures above $300 \mathrm{C}$. That is more than twice the activity of previous HC SCR materials. These materials are candidates
\end{abstract}


for emission control on heavy-duty systems (i.e.; over 8500 pounds gross weight). Tests of one of the downselected materials on an engine dynamometer show NOx reductions greater than $80 \%$ under some conditions even though the net NOx reductions on the HWFET and the US06 cycles were relatively low. The program is scheduled to continue until the end of the 2006 calendar year. Work in the final year will focus on continued discovery and identity of candidate materials, and also on refining the engine operating strategies to increase NOx reduction over a full engine cycle. 


\section{TABLE OF CONTENTS}

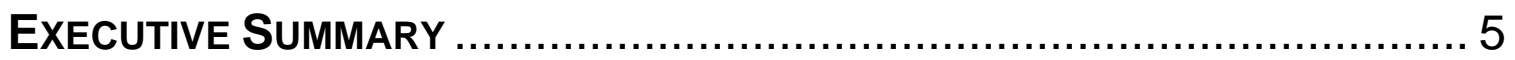

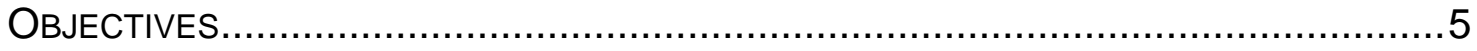

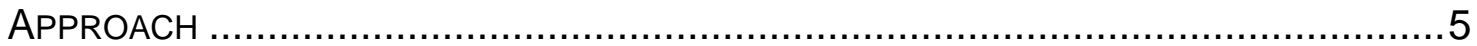

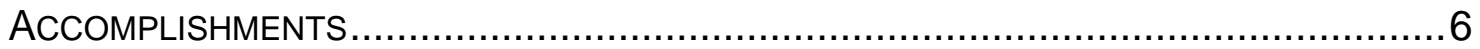

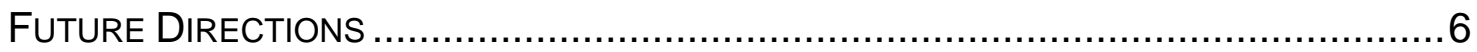

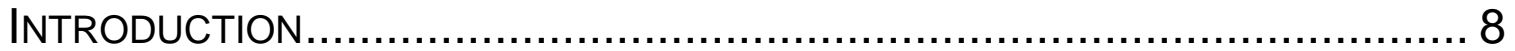

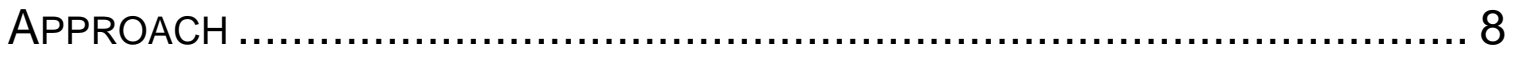

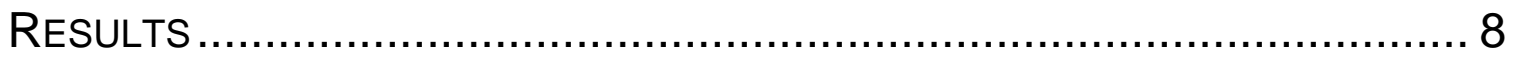

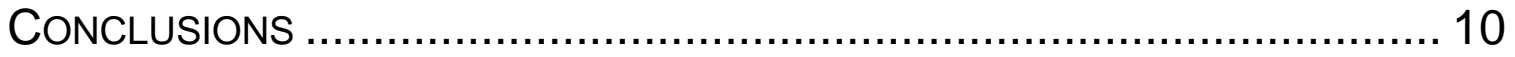

FY 2005 PRESENTATIONS ...................................................... 11

\section{TABLE OF FIGURES}

Figure 1. Schematic of the NOx discovery program and the separation of the tasks within the program.

Figure 2. Comparison of urea SCR, HC SCR old technology and the fast throughput technology (new material). The HC SCR materials are coated on monoliths.

Figure 3. Schematic shows the test cell design for measurement of emission reduction technology using the full size HC-SCR converters. TEX indicates species detectors for the emissions at various points within the aftertreatment system. $\mathrm{HC}$-INJ indicates a system for controlled injection of hydrocarbons into the exhaust stream.

Figure 4. Picture of the aftertreatment rack in the test cell designed for the full size HC-SCR converters and flexibility for the change and modification of the aftertreatment architecture.

Figure 5. Graph of the instantaneous NOx conversion for this HC-SCR dyno measurement over a part of the US06 test cycle. For presentation convenience, the miles per hour in the test cell is multiplied by -100 to move it off the graph of the NOx conversion. 


\section{Executive Summary}

\section{Objectives}

Develop new NOx selective catalytic reduction (SCR) catalysts that can operate in the lean exhaust of diesel or lean gasoline engines. These catalysts can:

- utilize the on board fuel (i.e.; HC SCR) as the reductant

- have NOx conversion activities in excess of $80 \%$

- span the operating range (e.g.; temperature and flow rate) for these lean engines

- have sufficient durability and resistance to poisoning to meet the $120 \mathrm{k}$ standard

\section{Approach}

- Use fast through put techniques to synthesize and measure the activities of a large range of materials for NOx reduction properties (Engelhard)

- Use design of experiment (DOE) and statistical analysis to predict optimum compositions from materials identified in the discovery (fast throughput) phase of materials evaluation using the CombiMat 2.5 database developed for this program (Accelrys and GM).

- Scale up, evaluate and do a feasibility analysis of potential NOx reduction catalysts identified from the discovery phase of the program

- Test the most promising materials on an engine 


\section{Accomplishments}

- Tested over 4500 materials for NOx reduction potential since the initiation of the program

- A series of loading studies on monolith cores with the first downselected material determined the composition for scale up to full size engine monoliths

- Four 5 liter monolith "bricks" were coated for engine testing using the first downselected catalytic material

- Tests of one of the downselected materials on an engine dyno show NOx reductions greater than $80 \%$ under some engine conditions even though the net NOx reductions on the HWYFET and the US06 cycles were relatively low.

- GM reactor using a hydrocarbon mixture of dodecane and xylene to simulate diesel fuel indicates what converter/engine conditions are necessary to increase the net NOx reduction.

\section{Future Directions}

- Modify the discovery system in order to use a simulated diesel fuel as the reductant

- Continue the discovery phase of the program to identify materials which increase the net NOx reduction using simulated diesel fuel

- Refine the engine operating strategy to increase the NOx reduction over a full engine cycle 
- Develop cold start/low temperature engine strategies to meet emission standards on a light duty FTP cycle 


\section{Introduction}

This GM project was initiated 8/16/02. Its goal is to develop new NOx reduction catalysts for lean combustion systems such as both light and heavy-duty diesels and for the stratified charge gasoline engines. These new catalysts are needed to enable these engines to meet the Tier II NOx standards for the North American markets that are being phased in over the time period between 2007 and 2010.

\section{Approach}

Selective Catalytic Reduction (SCR) with reductants from the fuel (HC-SCR) is the technology that is focus of the development of the new catalytic materials. The approach is to use high throughput technology to develop the new materials (Engelhard), informatics to mine the data arising from the fast throughput experimentation (Accelrys and GM) and classic reactor evaluation to determine the suitability of the new materials for automotive applications (GM and Engelhard). Figure 1 shows the structure of the responsibilities within the program.

\section{$\underline{\text { Results }}$}

To date at Engelhard, over 4500 new materials have been evaluated on the discovery system since the initiation of the program. We have downselected over a 100 of these materials for detailed laboratory reactor study. Our original 
selection of a reductant for this study was n-octane which is representative of the long chain alkanes in typical diesel fuel. Based on those detailed reactor studies the program has developed materials that give conversions more than twice as efficient as the industry standard for HC-SCR and compares favorably with urea SCR for high temperature applications (see figure 2). To date the results from this approach have identified at least two materials that have been downselected for intensive feasibility analysis. These intensive feasibility analysis studies have included reactor studies with a simulated diesel fuel, coating and canning of the materials on full size monolith bricks and engine testing of these catalysts.

Testing of these materials on GM reactors has evolved from n-octane to using a simulated diesel fuel comprised of 67 vol\% n-dodecane and 33 vol\% m-xylene ( ${ }^{\text {sim }}$ diesel1). Results on the GM reactor using the simulated diesel fuel are found to be consistent with the engine experiments on the dyno at GM using the canned full size converters coated with the first downselected material.

The catalyst/dyno setup is shown in figure 3 . The converter can contains two five liter monoliths for engine testing. This design includes a DOC to clean up the engine out hydrocarbons and a dosing system for controlled addition of hydrocarbon to the SCR catalysts. The mixer is added to ensure full vaporization of the fuel before the HC-SCR catalyst. This system is designed for flexibility for modification of the architecture of the experimental aftertreatment system (see figure 4). 
This dyno test system has been used to evaluate the effects of hydrocarbon dosing ( $\mathrm{C} / \mathrm{N}$ ratios), oxygen concentrations, space velocities and transient effects in the engine environment. Instantaneous NOx conversions measured on the US06 (figure 5) shows conversions consistent with the high conversions observed from the laboratory reactor experiments (figure 2). This first set of engine tests has initiated changes in the conditions that are being used on the discovery system and the conditions that are being used to test scaled up materials in the GM reactors.

Engelhard is permitted to sell catalyst products developed under this program to other automotive customers.

\section{Conclusions}

High throughput discovery approaches are being applied to finding new NOx reduction catalytic materials that use fuel as the reductant. This approach has tested over 4500 materials for NOx reduction potential in approximately 30 months using n-octane as the reductant. Full size monolith bricks were coated with some of these materials for engine testing. Tests of those bricks on an engine dyno show NOx reductions greater than $80 \%$ under some engine conditions demonstrating a potential for these materials as lean NOx reducing catalysts. Recent GM reactor testing using a hydrocarbon mixture of dodecane and xylene to simulate diesel fuel shows what engine conditions are needed to develop a viable NOx reducing system using these catalysts. Further testing is 
planned to demonstrate the efficacy of these materials as NOx reduction catalysts for lean combustion systems.

\section{FY 2005 Presentations}

1. "Update on HC-SCR Combinatorial Studies", Eighth CLEERS (Cross-Cut Lean Exhaust Emissions Reduction Simulation) Workshop, University of Michigan-Dearborn, May 17-19, 2005.

2. "Discovery of New NOx Reduction, Hydrocarbon SCR Catalysts using High Throughput Technologies", the Society of Automotive Engineers (SAE), Government/Industry Meeting, Washington D.C., May 9-11, 2005

3. "Discovery of New NOx Reduction, Hydrocarbon SCR Catalysts using High Throughput Technologies", Gordon Conference on Combinatorial \& High Throughput Materials Science, Queens College, Oxford, UK, August 14-19, 2005. 


\section{Figures with captions}

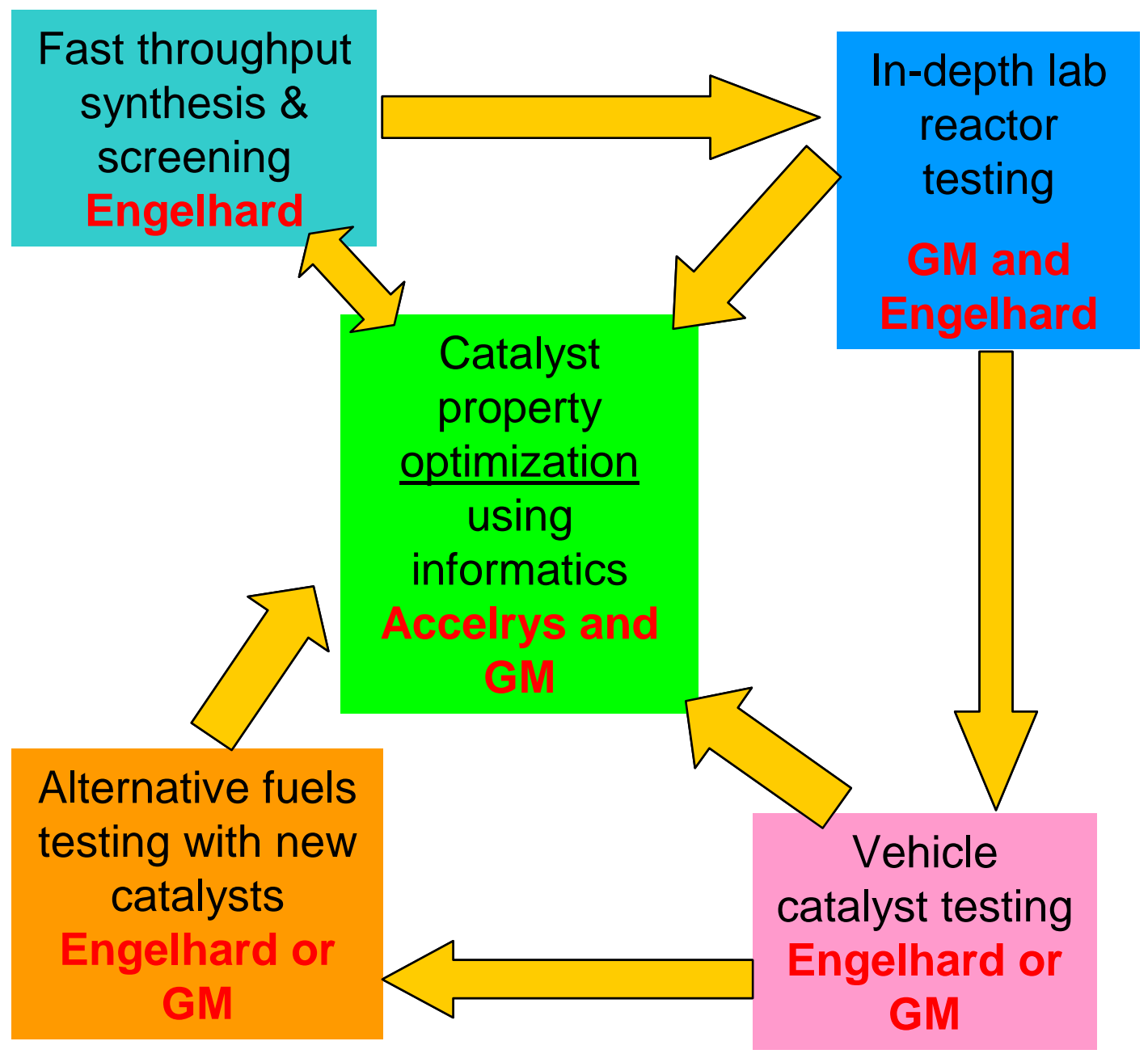

Figure 1. Schematic of the NOx discovery program and the separation of the tasks within the program. 


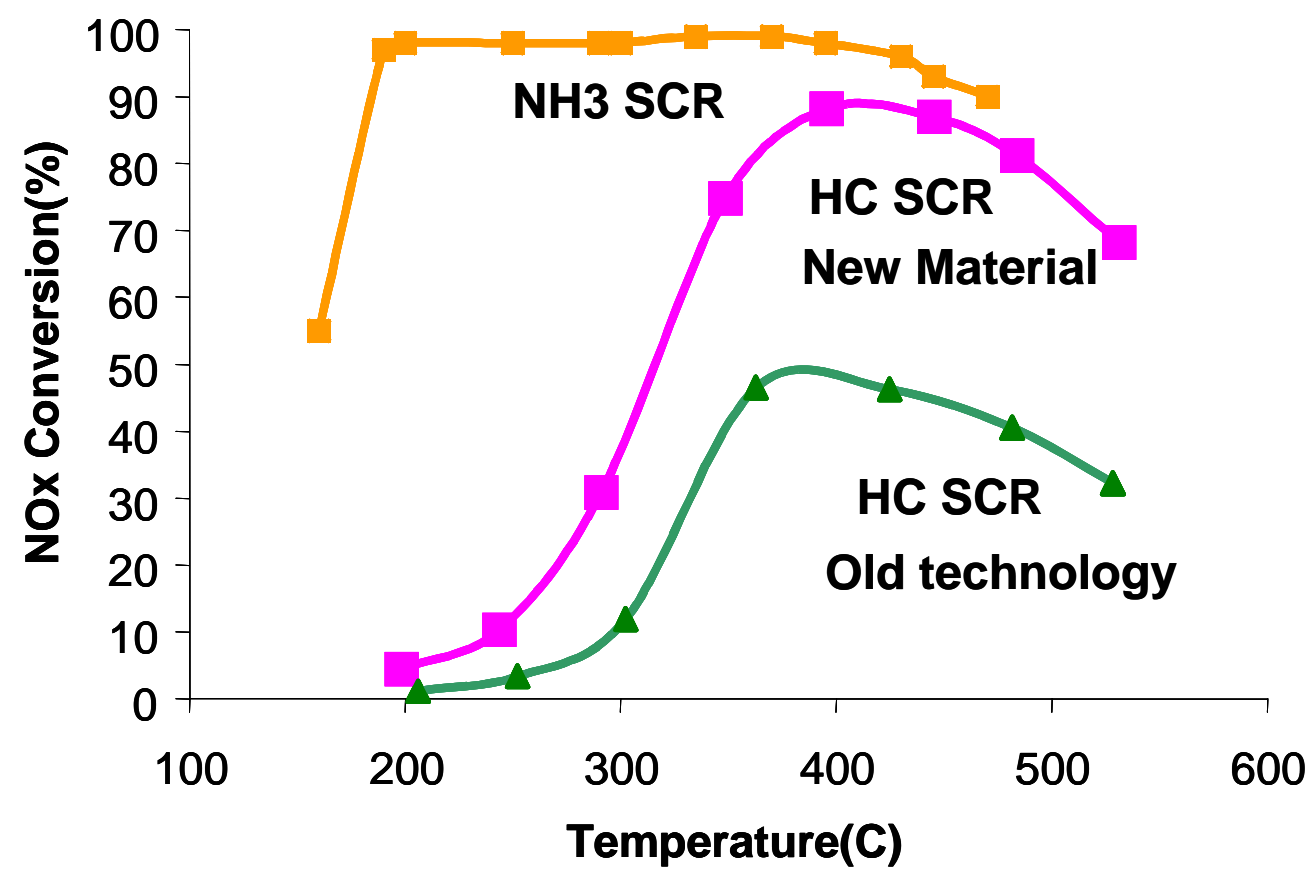

Figure 2. Comparison of urea SCR, HC SCR old technology and the fast throughput technology (new material). The HC SCR materials are coated on monoliths.

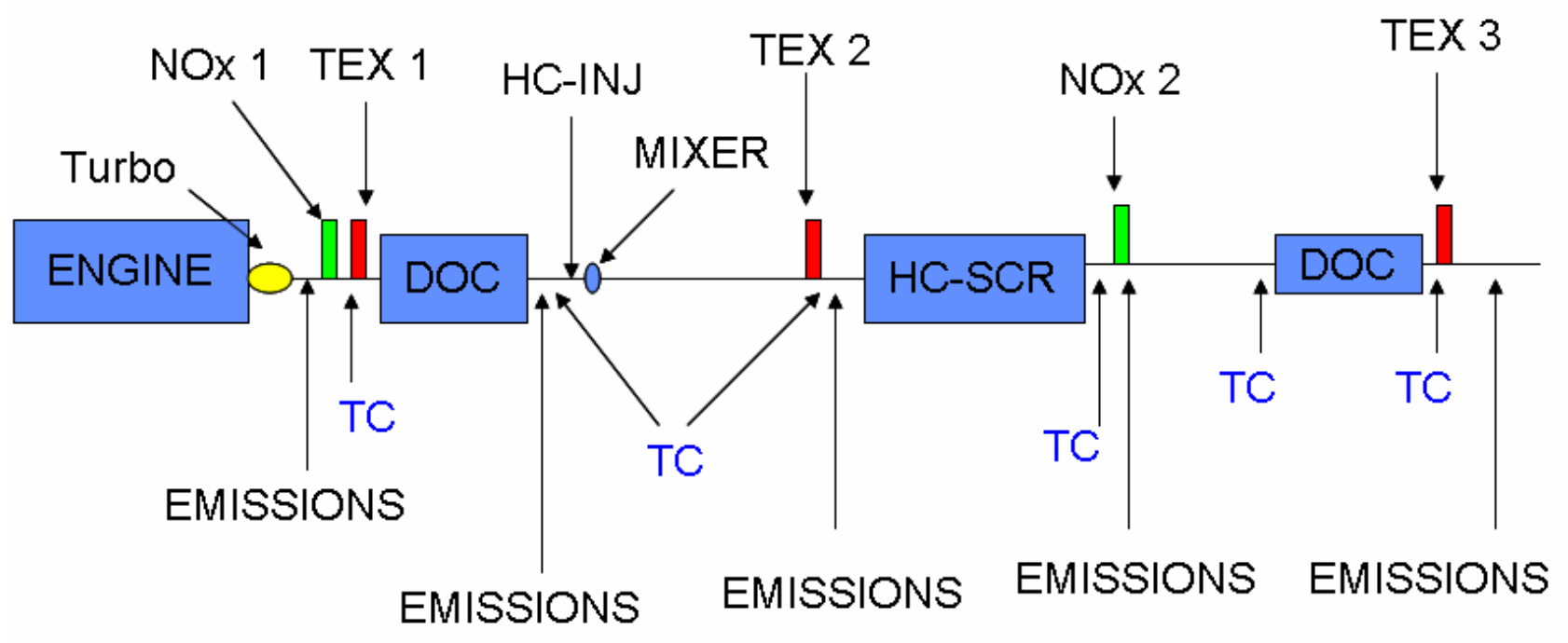

Figure 3. Schematic shows the test cell design for measurement of emission reduction technology using the full size HC-SCR converters. TEX indicates species detectors for the emissions at various points within the aftertreatment system. HC-INJ indicates a system for controlled injection of hydrocarbons into the exhaust stream. 


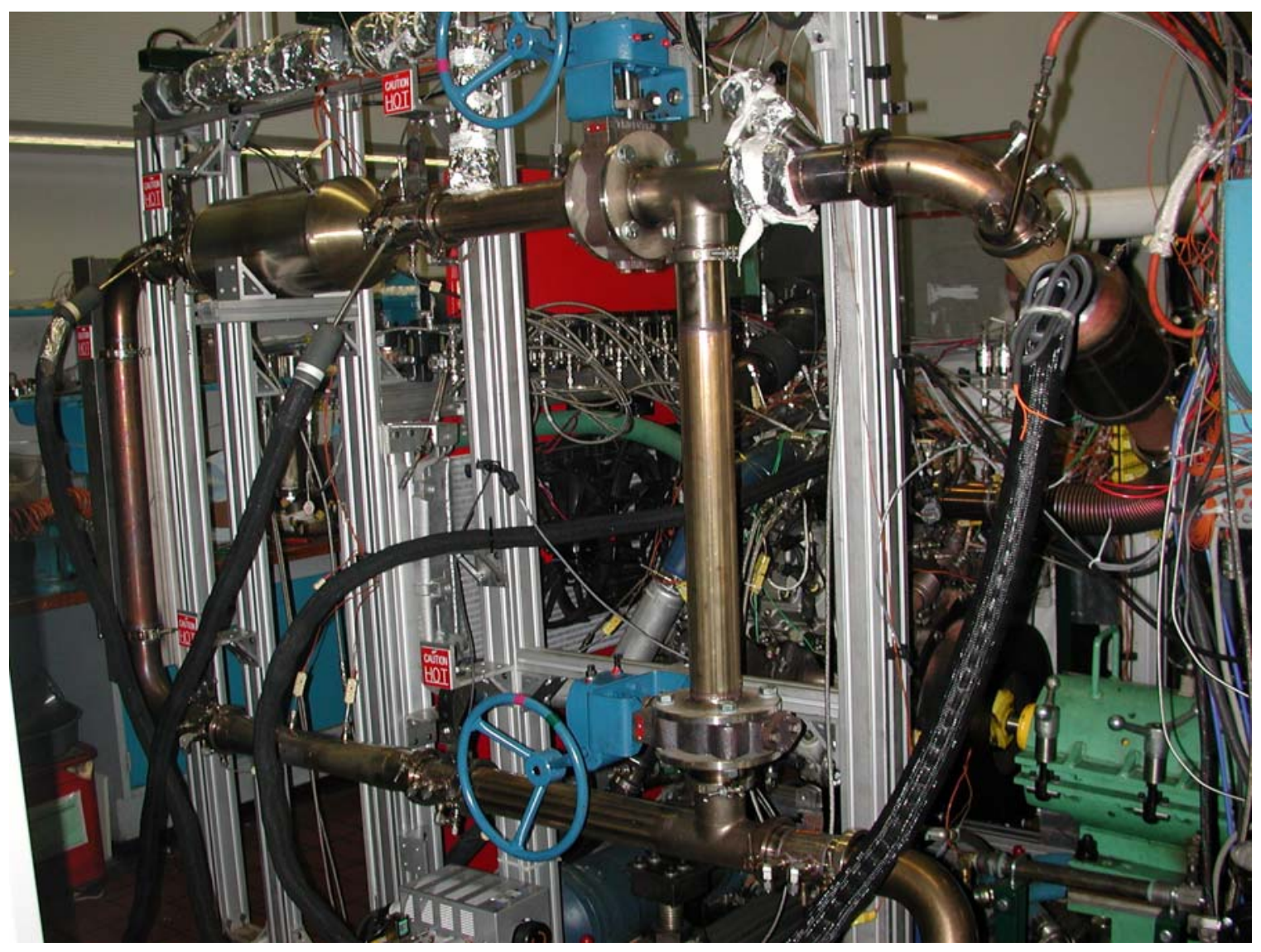

Figure 4. Picture of the aftertreatment rack in the test cell designed for the full size HC-SCR converters and flexibility for the change and modification of the aftertreatment architecture. 


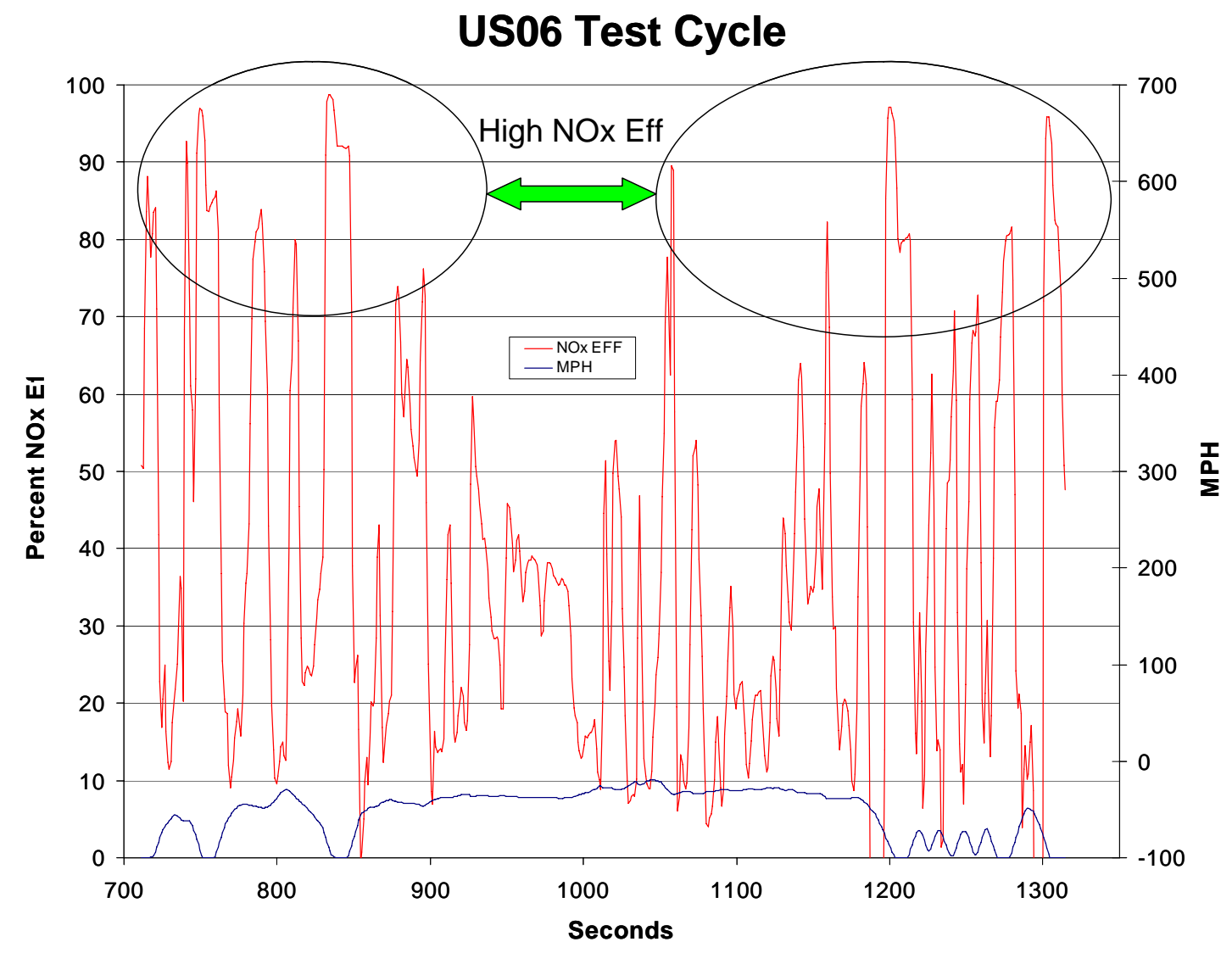

Figure 5. Graph of the instantaneous NOx conversion for this HC-SCR dyno measurement over a part of the US06 test cycle. For presentation convenience, the miles per hour in the test cell is multiplied by -100 to move it off the graph of the NOx conversion. 